\title{
Managing intellectual property rights over clinical trial data to promote access and benefit sharing in public health
}

\section{Pamela Andanda,}

School of Law, University of the Witwatersrand, Johannesburg and Visiting Research Fellow, World Trade Institute, Bern

\begin{abstract}
There are ongoing debates regarding the nature and scope of intellectual property protection, if any, which clinical trial data should receive in terms of Article 39 of the TRIPS Agreement. These debates however occur in the international and bilateral contexts thus excluding key stakeholders in public health and clinical research. The roles and experiences of excluded stakeholders such as technology transfer managers, clinical researchers and regulatory authorities hardly feature in these debates. The debates raise pertinent ethical and legal concerns, which warrant considerations of the strategies that can be used to manage intellectual property rights over clinical trial data with a view to fostering access and benefit sharing in public health. This paper suggests roles that the excluded stakeholders can play in the strategic management of intellectual property rights over clinical trial data in order to cater for public health needs. The concept of access and benefit sharing, which has so far been debated in the fields of biodiversity and most recently in the human genome context is applied to public health with a view to initiating discussions on how it can inform decision-making in the management of intellectual property rights over clinical trial data.
\end{abstract}

\section{Introduction}

Intellectual property rights (IPRs) play an important role in many sectors of the society. Public health is one such sector, which is however, very sensitive to the manner in which IPRs are managed. This is the case because, as Tansey has accurately observed, 'health is just one area affected by struggles over who will control and benefit from the scientific and technological changes underway., ${ }^{1}$

Taubman's very humorous observation regarding the international scope of public health concerns is equally very relevant for appreciating the need to manage IPRs with a view to promoting access and benefit sharing (ABS) in public health:

'Pathogens show scant respect for national boundaries, human physiology is not shaped by national allegiance, and the flow of medical science is not neatly confined to discrete

\footnotetext{
${ }^{1}$ Tansey G, Introduction: Legal Fictions and Public health, in Roffe P, Tansey G and Vivas- Eugui (eds) Negotiating Health: intellectual property and access to medicines. Earthscan, London 2006, p.2.
} 
jurisdictions. The struggle to combat human disease and to promote health is inherently international in character and is recognized as an element of maintaining international peace and security. ${ }^{2}$

The above observation seems to be a good justification for data sharing among clinical researchers yet 'IPR is often cited as a reason why results cannot be disseminated, resulting in a potential conflict between the principle of sharing data and a system that supports wealthcreation by protecting intellectual property. ${ }^{3}$ Collaboration is essential in public health particularly if ABS has to be achieved and it has been noted that the success of collaborative initiatives 'between pharmaceutical companies, biotechnology firms and public research organisations...depends on developing strategies to manage access to proprietary knowledge and to share the benefits of discoveries from its use. ${ }^{4}$

The unwillingness to share data freely certainly means that some researchers consider their data proprietary 'with a competitive advantage over other groups in terms of discovery and further acquisition of funds that would expand their research operations. ${ }^{5}$ A possible reason for some researchers withholding data from their colleagues is the widespread practice of granting exclusive rights over clinical trial (CT) data. This is evident, for instance, from the pharmaceutical industry’s concern that the ‘[d]isclosure of information about clinical trials (even without going as far as results disclosure) involves making public what industry refers to as 'the art of drug development'." 6 The industry argues that the '[d]isclosure of such information, particularly early in the clinical trial process, may result in a loss of competitive advantage, which may deter companies from investing in drug development. ${ }^{7}$

Intellectual property management has been identified as an important tool that can be used by research consortium 'to maximize the chances of translating research findings into diagnostics, pharmaceuticals or vaccines. ${ }^{, 8}$ When intellectual property issues come into play, the situation calls for maintaining a delicate balance between protecting commercial interests

\footnotetext{
2 Taubman A, The international patent system and biomedical research: reconciling aspiration, policy and practice, The American Association of Pharmaceutical scientists Journal 2008, vol.10 (4): 526-536 at 526.

${ }^{3}$ Forward Look - Investigator-Driven Clinical Trials, the European Science Foundation (2009), p.10 Available at < http://www.esf.org/fileadmin/links/EMRC/FL_IDCT.pdf> accessed 23 September 2011

${ }^{4}$ Organisation for Economic Co-operation and Development (OECD), The Bioeconomy to 2030: designing a policy agenda. OECD Publishing, 2009, p.152.

${ }^{5}$ EC Ad Carvalho, AP Batilana, J Simkins, H Martins, J Shah et al., 'Application Description and Policy Model in Collaborative Environment for Sharing of Information on Epidemiological and Clinical Research Data Sets' (2010) 5(2) PLoS ONE: e9314. doi:10.1371/journal.pone.0009314

${ }^{6}$ Draft Issue Identification Paper: Registration and Disclosure of Clinical Trial Information, Health Canada (2005), p. 16. Available at http://www.hc-sc.gc.ca/dhp-mps/alt_formats/hpfbdgpsa/pdf/prodpharma/draftiipctrd_june_ddeebaucheedec_juin_2005-eng.pdf

${ }^{7}$ Health Canada (2005), p.16.

${ }^{8}$ Chokshi DA, Parker M and Kwiatkowskia DP, Data sharing and intellectual property in a genomic epidemiology network: policies for large-scale research collaboration, Bulletin of the World Health Organization 2006, vol. 84:382-387 at 383.
} 
and promoting public health. This balance is important in view of the debates over the nature of IP protection, which CT data should be accorded under the international and national legal frameworks. In current literature, little attention has been paid to the fact that data exclusivity may impede efforts by clinical researchers, regulatory authorities and other stakeholders to ensure benefit sharing with clinical research participants. This is essentially a public health concern, which seems to be overshadowed by preoccupation with wading off unfair competition from the generic industry. A balance also needs to be struck between the need for confidentiality and the need to foster academic freedom/ability to publish and disseminate research results and to promote public welfare. ${ }^{9}$

It is worth noting, as Pugatch has correctly observed, that the ongoing debate over data exclusivity 'seems to mark a shift from the conventional debates over patent protection and drug prices... [as it] involves both developed and developing countries, is characterized by political and economic interests, as well as by safety issues that guarantee to make it one of the more interesting as well as heated subjects in the IPR field. ${ }^{10}$

A lot has been written on the underlying problems with protecting CT data. ${ }^{11}$ It may thus be akin to opening a can of worms to delve into these debates in the context of public health in this paper. Consequently, the paper does not delve into such underlying problems but aims at suggesting ways in which IPRs over CT data can be managed by collaborating researchers, technology transfer offices (TTOs) and regulatory authorities in a manner that fosters ABS in public health. The underlying concerns that arise from these debates are however useful for informing the management options that are proposed in this paper. For

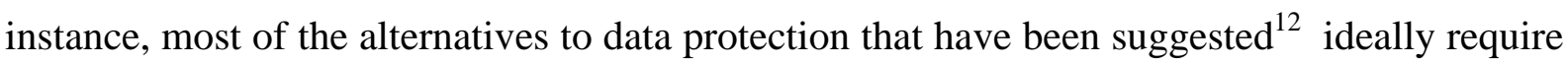
the direct involvement of the stakeholders that this paper focuses on, yet very little has been written on the role of these relevant stakeholders. The paper calls for the inclusion of the novel ethical principle of benefit-sharing (BS) in the ongoing debates as a way of giving public health concerns the importance that they deserve.

\footnotetext{
${ }^{9}$ Leibowitz K and Sheckler V, Negotiating clinical trial agreements, The Regulatory Affairs Journal (RAJ) Devices Sept/Oct 2006: 289-292 at 289.

${ }^{10}$ Pugatch MP, Intellectual Property, Data Exclusivity, Innovation and Market Access, in Roffe P, Tansey G and Vivas- Eugui (eds) Negotiating Health: intellectual property and access to medicines. Earthscan Publications, London, 2006, p.129.

${ }^{11}$ See Reichman HJ, Rethinking the Role of Clinical Trial Data in International Intellectual Property Law: The Case for a Public Goods Approach, Marquette Intellectual Property Law Review 2009, vol. 13(1):1-68 and Taubman A, Unfair competition and the financing of public-knowledge goods: the problem of test data protection, Journal of Intellectual Property Law \& Practice, 2008, Vol. 3(9):591-606.

${ }^{12}$ Weissman R, Data Protection: Options for Implementation, in Roffe P, Tansey G and Vivas- Eugui (eds) Negotiating Health: intellectual property and access to medicines. Earthscan Publications, London, 2006, pp.151-178.
} 
The first part of the paper discusses the nature of CT data and the public health implications of protecting such data through IPRs. The manner in which different approaches to CT data protection have been shaped by debates at the international level is discussed in the second part. ABS and public health concerns that arise from protecting CT data are discussed in the third part, which lays the foundation for the discussion of how to manage these complex concerns in the fourth part of the paper. Some thoughts on how to move forward are provided in the concluding section of the paper.

\section{The nature of CT data and the implications of its protection through IPRs}

CT data is '...data resulting from clinical trials of drugs...' 13 Taubman provides a very useful analysis of the type of information that CT data may contain. He argues that 'The information content of test data can be viewed (and regulated) at several levels: (i) as empirical information about the physical properties of chemical substances; (ii) as information that test data establish a substance as safe, acceptably non-toxic, sufficiently efficacious, etc.; (iii) as information that the substance is approved for use by a certain regulator on the basis of test data submitted. ${ }^{14}$ His observation that '...it is easier to exclude access to information at level (i) than at levels (ii) or (iii), and a rival product may be approved without direct reference to level (i) at all ${ }^{, 15}$ is key to the discussions about the ethical implications of protecting CT data, which are considered in this paper.

Clinical research warrants careful attention due to the important role that it plays in public health. The use of human volunteers as participants and researchers' dependence on the results to inform medical decisions imply that clinical research is very important for public health. ${ }^{16}$ Clinical research is also important for measuring and obtaining the safety and data necessary for seeking marketing approval of drugs and devices. ${ }^{17}$ Two reasons have been given in literature to support broader disclosure and dissemination of data:

'Trial participation by humans is predicated on the concept that the trial will add to "medical knowledge," which requires dissemination of the results. In addition, it is not possible for a volunteer or an IRB [institutional review board] to assess the risks and benefits of participation in a clinical trial if an unknown proportion of data on the proposed interventions is not publicly available. ${ }^{, 18}$

\footnotetext{
13 Taubman (2008), p. 591.

14 Taubman (2008), p. 591.

15 Taubman (2008), p. 591.

${ }^{16}$ Zarin DA and Tse T, Moving Toward Transparency of Clinical Trials 7 March 2008 Science 319: 1340-1342.

${ }^{17}$ Leibowitz and Sheckler (2006), p. 289.

${ }^{18}$ Zarin and Tse (2008), p.1342.
} 
Two fundamental principles have also been proposed by Chokshi and colleagues as the basis for decisions about data sharing and intellectual property:

'(1) impediments to innovation in research processes should be minimized, and (2) the fruits of research - eventual products that result from scientific discoveries — should be made as widely accessible as possible, particularly to the people who need them the most. $^{19}$

The above principles have been suggested in the context of genomic epidemiology but the same can be applied generally to clinical research as well.

Regulatory authorities grant marketing authorization based on the provided CT data. As such, 'the availability of the data is a condition for obtaining marketing approval of new products, modifications or new uses of existing products. ${ }^{20}$ The emerging practice of providing sui generic protection of CT data is therefore a real concern since, as Correa correctly observes, it implies that 'the research-based pharmaceutical... industry, actively seeks to ensure a period of exclusive use of the data after marketing approval. During this period, national authorities would be prevented from using or relying upon the data for marketing approval of generic versions of the already registered products. ${ }^{21}$

Sui generic protection of CT data warrants a consideration of how data exclusivity differs from patents in order to appreciate the magnitude of the problem. The difference that Pugatch provides is this:

'Patents are granted to the inventions and innovations embodied in a new medicine, [while]... data exclusivity is aimed at protecting and safeguarding the proprietary know-how and information included in the registration files against any type of unfair commercial use. ${ }^{22}$

There are different views on the scope of protection that should be given to test data. ${ }^{23}$ These divergent views could be attributed to the fact, as Taubman observes, that TRIPS created 'strong expectations of effective protection of regulatory data, but did not reconcile the differing views on the appropriate scope of protection that emerged during the TRIPS negotiations. ${ }^{24}$ As a result of divergent practices, different countries protect regulatory data

\footnotetext{
${ }^{19}$ Chokshi DA, Parker M and Kwiatkowskia DP, Data sharing and intellectual property in a genomic epidemiology network: policies for large-scale research collaboration, Bulletin of the World Health Organization 2006, vol. 84:382-387 at p. 383.

${ }^{20}$ Correa MC, Protecting Test Data for Pharmaceutical and Agrochemical Products under Free Trade Agreements, in Roffe P, Tansey G and Vivas- Eugui (eds) Negotiating Health: intellectual property and access to medicines. Earthscan Publications, London, 2006, p.82.

${ }^{21}$ Correa (2006), p.83.

22 Pugatch (2006), p.100.

${ }^{23}$ See Reichman JH, The International Legal Status of Undisclosed Clinical Trial Data: From Private to Public Goods? In Roffe P, Tansey G and Vivas- Eugui (eds) Negotiating Health: intellectual property and access to medicines. Earthscan Publications, London, 2006, pp.133-150.

${ }^{24}$ Taubman (2008), p. 594.
} 
for different periods. ${ }^{25}$ This is evident from the following three main approaches to data exclusivity that are used in different regimes: ${ }^{26}$

a) Generic manufacturers have to generate their own data (for products that are off patents) in countries such as USA, Europe and Japan since they cannot rely on the data submitted by the first applicant;

b) Countries such as Argentina, Brazil and Israel allow regulatory authorities to rely on the data submitted by the first applicant for a similar product, provided that its physicochemical attributes are equivalent to the first applicant's;

c) Regulatory authorities may also opt 'to rely upon an approval granted in a foreign country...,27

\subsection{The consequences of data exclusivity on Public health}

Data exclusivity has two consequences on public health. First, generic drug companies cannot obtain marketing approval for generic drugs on the basis of the protected CT data during the period of exclusivity. ${ }^{28}$ Secondly, compulsory licensees may also be precluded from getting their products approved during the data exclusivity period. ${ }^{29}$ These consequences essentially mean that generic drug companies and compulsory licensees are compelled to duplicate clinical trials in order to produce their own test data. Correa argues that 'the duplication of preclinical and/or clinical trials to develop anew the test data necessary for the approval of a drug also raises ethical concerns and generates an additional obstacle for generic competition. ${ }^{30}$

Without a proper interpretation and understanding of the scope of CT data protection under Article 39.3 of TRIPS, public health implications are far more serious. The Brazilian experience provides a clear example in this regard. The interpretation of Article 39.3, which was until recently favoured in Brazil was that test data that is submitted to the Brazilian National Health Surveillance Agency (Agência Nacional De Vigilância Sanitária, hereinafter Anvisa), for marketing approval 'is protected by Brazilian law and cannot be used by Anvisa or any third party for any subsequent marketing approvals whatsoever, except when

\footnotetext{
${ }^{25}$ See Pugatch (2006), pp.101-110 for a detailed discussion of these approaches at the domestic and international levels.

${ }^{26}$ Correa (2006), p.83.

${ }^{27}$ Correa (2006), p.84.

${ }^{28}$ Correa (2006), p.89.

${ }^{29}$ Correa (2006), p.91.

${ }^{30}$ Correa (2006), p.93.
} 
previously authorized. ${ }^{31}$ Di Blasi offers the following arguments in support of this interpretation: first, Anvisa's reliance on the test data would constitute 'unfair commercial use' in so far as the registering competitor would have a low production cost. Secondly, the use of previously generated test data may pose a threat to safety and efficacy since 'the formulation of generic and similar copies can actually differ... in terms of quality control of the active principle ingredients and vehicles, which can impact bioavailability' and thirdly, the protection of such data 'is fundamental to the financial compensation of all investments made by the sponsor company. ${ }^{, 32}$

The above interpretation was recently subjected to judicial testing in the famous antidepressants case, the National Health Surveillance Agency (ANVISA) and Lundbeck ${ }^{33}$, which was heard by the Federal district court and the Superior Court of justice. ${ }^{34}$ The case before the courts involved the registration of generic and similar medicines based on the active ingredient, escitalopram, an antidepressant. The Federal court judge had found that Anvisa had violated Article 39.3 of TRIPS and ordered Anvisa to refrain from granting registration to an unauthorized third party if they used the test results and data of the dossier sent by Lundbeck Brazil Ltda., the producer of Lexapro, a reference drug, to receive the registration for the drug. The court also ruled that 'any drug registration already granted based on this dossier, in particular those obtained by companies Aché Pharmaceutical Laboratories S/A and Biosintética Pharmaceuticals Ltd., Manufacturers of similar drugs’ were invalid., ${ }^{35}$

In August 2011, the Superior court of Justice suspended the Federal court's decision on the basis that its enforcement 'would have caused harm to public policy, [and] put Brazil's generic drug market at risk and damaged the economy. ${ }^{36}$

As a result of the Superior court of Justice's decision, the biotechnology industry in the USA has recommended, to the United States Trade Representative, that Brazil be elevated to the 'Priority Watch List. ${ }^{, 37}$ The industry is concerned that 'Brazil's lack of data protection

\footnotetext{
${ }^{31}$ Di Blasi G, Data exclusivity protection in Brazil, World Intellectual Property Review, November/December (2009): 32-35 at p.35. TRIPS Agreement has been incorporated into the Brazilian law by virtue of Decree number 1355.

${ }^{32}$ Di Blasi (2009), p.34.

${ }^{33}$ The National Health Surveillance Agency (ANVISA) and Lundbeck case, World Intellectual Property Review, November/December (2011): 29.

${ }^{34}$ Brazilian Court rejects data exclusivity, accessed at http://donttradeourlivesaway.wordpress.com/2011/08/24/brazilian-court-rejects-data-exclusivity/ on $27^{\text {th }}$ February 2012.

${ }^{35}$ Brazilian Court rejects data exclusivity (2011).

${ }^{36}$ World Intellectual Property Review, November/December (2011): 29.

${ }^{37}$ These are countries that are considered to have 'serious IPR deficiencies that warrant increased bilateral attention concerning the problem areas or practices.' See Masterson JT, Enforcement of Trademarks and copyright under the WTO agreement on Trade-related Aspects of intellectual property rights, in Masterson JT (ed), International trademarks and copyright enforcement and management, American Bar Association
} 
for pharmaceuticals is inconsistent with TRIPS Article 39. ${ }^{38}$ The industry equally considers the decision to have been made purely on 'political grounds.'

The Superior court of Justice's decision certainly entailed a balancing act in respect of which socio-economic, ethical and human rights considerations were brought to bear. Such factors cannot accurately be considered as purely political in nature.

The consequences of Brazil remaining on the Priority Watch List should not however be underestimated because under section 301 of the US Trade Act of 1974, the USTR can use its annual review process to initiate WTO dispute settlement proceedings against countries whose IPR practices are inconsistent with TRIPS or it can eliminate unilaterally granted tariff preferences or impose unilateral trade sanctions if the country in question is not a member of the WTO. ${ }^{39}$ The Superior court of Justice's decision is therefore commendable for putting socio-economic, ethical and human rights considerations before trade interests. It should also provide a clear example of the correct interpretation of Article 39.3 of TRIPS, which should not be read to provide for data exclusivity.

\subsection{Ethical implications of granting exclusive rights over CT data}

In view of the fact that Article 39.3 of TRIPS does not confer exclusive rights on CT data, Reichman argues that a state 'remains free to make noncommercial uses of the data and to make other uses of them that are "fair," even if such uses produce a commercial impact. For example, governmental use to avoid health or safety risks revealed by the data in the local environment are fair by definition. ${ }^{40}$ He equally argues that 'the promotion of research and science in the public interest would presumably allow some uses of the data that would be both non-commercial and fair, consistent with any research exemption embodied in the domestic patent laws. ${ }^{41}$

WTO member states however need to beware of incurring liability as a result of TRIPplus obligations that they have contracted through Free Trade Agreements (FTAs). In practice, some clinical researchers also tend to relinquish their entitlements, to rely on their domestic laws, by signing clinical trial agreements in terms of which they agree to be governed by the laws of their foreign sponsors rather than their domestic laws. In such cases,

Publishing, Chicago, 2004, p.20. Argentina, Brazil, Canada, Chile, China, India, Indonesia, Israel, Thailand and Venezuela are currently on this list.

${ }^{38}$ Biotechnology Industry Organisation, 2012 special 301 submission to the Office of the United States Trade Representative, Docket no. USTR-2011-0021, p.11. Available at http://www.bio.org/sites/default/files/2012\%20BIO\%20Submission.pdf

39 Masterson (2004), p.21.

${ }^{40}$ Reichman (2009), p.19.

${ }^{41}$ Reichman (2006), p.141. 
if the sponsor's laws confer exclusive rights over CT data, then Reichman's arguments may not be of much help to such member states or clinical researchers who are bound by the contracted TRIPS-Plus obligations.

In situations where the data generator's competitors are compelled to duplicate preclinical and/or clinical trials to develop new test data, very pertinent ethical issues arise. For instance, is it ethical to duplicate clinical trials using a placebo or lower standards while 'the best current proven intervention', as required by paragraph 32 of the Declaration of Helsinki, exists but such best intervention is the subject of exclusive rights that cannot be availed to the competitors?

For purposes of putting the discussion of the ethical implications in context, a brief explanation of the status of the Declaration of Helsinki (DOH) suffices here. The DOH is widely accepted ethics guidance and some of its sections have been incorporated in other international and national instruments, guidelines, laws and regulations relating to research on human participants. ${ }^{42}$ The general understanding is that ethics guidelines are not legally binding but it should be noted that such guidelines are regarded in current legal literature as customary international law. ${ }^{43}$ An ethics guideline must be supported by the consistency and generality of a practice to qualify as customary international. ${ }^{44}$ Some general and consistent state practices can be gleaned in the government funding of national and international clinical trials. $^{45}$

Paragraph 32 of the Declaration of Helsinki provides as follows:

'The benefits, risks, burdens and effectiveness of a new intervention must be tested against those of the best current proven intervention, except in the following circumstances:

- The use of placebo, or no treatment, is acceptable in studies where no current proven intervention exists; or

- Where for compelling and scientifically sound methodological reasons the use of placebo is necessary to determine the efficacy or safety of an intervention and the patients who

\footnotetext{
${ }^{42}$ Delon Human \& Sev. S Fluss 'The World Medical Association’s Declaration of Helsinki: Historical and Contemporary Perspectives’. Available at http://www.wma.net/en/20activities/10ethics/10helsinki/draft_historical_contemporary_perspectives.pdf ${ }^{43}$ Andanda P, chaturvedi S, Mengesha E and Schroeder D 'Legal Background: Convention on Biological Diversity, Declaration of Helsinki and other Relevant Guidelines’. In Schroeder D and Cook-Lucas JM (eds) Benefit Sharing: A Short Handbook for Users of Biological Resources (forthcoming from Springer in 2012). ${ }^{44}$ Brownlie I, Principles of Public International Law, 2003 Oxford, Oxford University Press, New York, p.7.

${ }^{45}$ Fidler DP, “ “Geographical Morality” Revisited: International Relations, International Law and the controversy over Placebo Controlled HIV Clinical Trials in Developing Countries’ 2001 Harvard International Law Journal vol. 42, p.326.
} 
receive placebo or no treatment will not be subject to any risk of serious or irreversible harm. Extreme care must be taken to avoid abuse of this option. ${ }^{46}$

Correa therefore correctly concludes that 'when test data for an approved drug already exists, repeating tests with placebo or otherwise creating risks for patients is clearly unethical and would be unacceptable under many health regulations. ${ }^{47}$

\section{Clinical trial data in the international context}

The TRIPS Agreement is considered 'the first multinational agreement ever to require... [test data] protection. ${ }^{48}$ It should however be noted, as Taubman correctly observes, that TRIPS 'is not a model IP law, and ... its text is ill suited to be converted directly into domestic legislation... ${ }^{49}$ This is the case because it 'is an international agreement between trading partners on what they can legitimately expect of one another as far as IP protection is concerned, and on the actions they can and cannot take when those expectations, inevitably, are significantly frustrated. ${ }^{50}$

Article 39.3 of TRIPS provides that

'Members, when requiring, as a condition of approving the marketing of pharmaceutical or of agricultural chemical products which utilize new chemical entities, the submission of undisclosed test or other data, the origination of which involves a considerable effort, shall protect such data against unfair commercial use. In addition, Members shall protect such data against disclosure, except where necessary to protect the public, or unless steps are taken to ensure that the data are protected against unfair commercial use.'

The purpose of Article 39.3 is to protect the undisclosed information, which is submitted for regulatory approval purposes against 'unfair commercial use'.51 For information to meet the requirements of the Article, it 'must be undisclosed (as defined in para[graph] 2) and the origination of data must result from a 'considerable effort. ${ }^{, 52}$

Paragraph 2 of the Article provides that the information shall be protected as "long as such information:

\footnotetext{
${ }^{46}$ World Medical Association, Declaration of Helsinki: Ethical principles for medical research involving human subjects. World Medical Association (2008). Available at http://www.wma.net/en/30publications/10policies/b3/. ${ }^{47}$ Correa (2006), p.93.

${ }^{48}$ Pugatch (2006), p.110.

49 Taubman A, A Practical Guide to Working with TRIPS. Oxford University Press, New York, 2011, p.12.

50 Taubman (2011), p.12.

${ }^{51}$ Abbott FM, The Cycle of Action and Reaction: Developments and Trends in Intellectual Property and Health, in Roffe P, Tansey G and Vivas- Eugui (eds) Negotiating Health: intellectual property and access to medicines. Earthscan Publications, London, 2006, p.32.

${ }^{52}$ Gervais D, The TRIPS Agreement: drafting history and analysis. Sweet and Maxwell, London, 2008 (3ed)., para 2.337
} 
(a) is secret in the sense that it is not, as a body or in the precise configuration and assembly of its components, generally known among or readily accessible to persons within the circles that normally deal with the kind of information in question;

(b) has commercial value because it is secret; and

(c) has been subject to reasonable steps under the circumstances, by the person lawfully in control of the information, to keep it secret.”

The protection, which Article 39 provides for is an intellectual property right since Article 1 (2) of the TRIPS Agreement defines the term 'intellectual property' to include all categories of IP that are the subject of Subsections 1 through to 7 of Part II and Article 39 falls within this range. The scope and the interpretation of Article 39.3 are rather contested. Correa, for instance, argues that the protection of test data does not confer exclusive rights in terms of Article 39.1, read together with Article 10bis of the Paris Convention for the protection of industrial property but only confers 'the right to take legal action against whoever has obtained commercial advantage by means of dishonest practice. ${ }^{53}$

Article 39.1 requires member states to protect undisclosed information against unfair competition as provided in Article 10bis of the Paris Convention ${ }^{54}$ if the information satisfies the requirements of paragraph 2 of the Article.

Two broad views exist regarding the status of clinical trial data in the current debates:

- Protecting CR data represents 'an attempt to create pragmatic mechanisms for financing specific public goods to respond to the market failure represented by reluctance to develop such data, to share it with regulators and other public interest users, and ultimately to bring new products to the market. ${ }^{, 55}$

- 'The drive to protect clinical trial data internationally is but the latest and most farreaching consequence of the deep structural problems that flow from the failure to treat clinical trials as a national and international public good. ${ }^{56}$

What seems common in the two approaches is the recognition of the public good nature of clinical trials, which is a good starting point, particularly for arguing in favour of data sharing on the basis of recognized research ethics principles, which are discussed in the next section of this paper.

Reichman observes that 'the demand for global protection of clinical test results arises from the underlying concerns about free-riding on private-sector research \& development ( $\mathrm{R}$

\footnotetext{
${ }^{53}$ Correa (2006), p.84.

${ }^{54}$ The Article prohibits any acts of competition that 'are contrary to honest practices in industrial or commercial matters...'

55 Taubman (2008), p.396.

${ }^{56}$ Reichman (2006), p.134.
} 
\& D) investments. ${ }^{57}$ Such underlying concerns are, for instance, evident in Taubman's argument that 'the absence of protection would create a manifest free-rider problem with deleterious impact on the public interest. ${ }^{58}$ What is at the centre of these observations is that there is an economic logic for protecting CT data. However, the economic logic of protecting CT data seems to be contested. For instance, Reichman notes that the estimated cost of US $\$ 800$ million to US \$1 billion per approved drug ${ }^{59}$ 'may be disputed at the margins, [as] it necessarily includes the cumulative high costs of clinical trials incurred for many drugs that fail to win approval. ${ }^{60}$ Most importantly, it has been established that pharmaceutical companies in the USA 'have never opened their books to independent public inspection to prove... [the R \& D costs]. ${ }^{, 1}$

\section{ABS and public health concerns}

ABS has so far been debated in the fields of biodiversity and most recently in the human genome contexts. Benefit sharing is a mechanism that can be used to counter the possibility of exploiting research participants since it means the '... provision of benefits to those who may lack reasonable access to resulting products and services. ${ }^{, 62}$

There are two relevant arguments for supporting BS in the context of clinical research, which are worth noting for the purposes of the discussion in this part of the paper. First, BS should be viewed as a 'compensatory activity, geared towards those who have taken risks and accepted the possible inconveniences that are necessary for research to take place and possibly succeed. ${ }^{63}$ This argument is plausible and can be used as a basis for supporting BS with research participants.

The second argument, which is based on the principle of solidarity, views BS 'as a social-and/or global-justice concern...[that] defines the way in which access to research results is provided or denied to everyone else. ${ }^{64}$ This argument can be used for urging BS in a broader context by including other parties such as collaborating researchers and the public in general as beneficiaries.

\footnotetext{
${ }^{57}$ Reichman (2006), p.134.

58 Taubman (2008), p. 596.

${ }^{59}$ DiMasi JA, Hansen RW and Grabowski HJ, The price of innovation: New estimates of drug development costs, Journal of Health Economics 2003 vol.22: 151-185. Cited in Reichman (2006), p.133.

${ }^{60}$ Reichman (2006), p.133.

${ }^{61}$ Light WD \& Lexchin J, Foreign free riders and the high price of US medicines, British Medical Journal 2005 vol. 331:958-60 at p. 959.

${ }^{62}$ Schroeder D, Benefit Sharing - High Time for a Definition. Journal of Medical Ethics 2007 vol. 33: 205-209 at 207.

${ }^{63}$ Simm K, Benefit-sharing: a look at the history of an ethics concern. Nature 2007 vol.8 (July): 496.

${ }^{64}$ Simm (2007), p.496.
} 
The rationale of extending the concept of ABS to clinical research may be questioned in view of the widespread belief 'that people participate in the research process out of 'altruism'.... ${ }^{65}$ However, there is evidence that 'a growing number of bioethicists, policymakers, legal scholars, patient groups, and other critically involved parties have recently, and vociferously, started calling for [the use of benefit-sharing as]... a new ethical principle to supplant the long-reigning notion of altruism, and to supplement the key tool in the bioethical toolbox, informed consent. ${ }^{, 66}$ Most importantly, the concept of benefit sharing has recently found its way into the clinical research context through the World Medical Association's (WMA) Declaration of Helsinki (the Declaration), which requires the provision of post-study access as a form of benefit-sharing.

Paragraph 30 of the earlier version of the Declaration (2000), provided that

'At the conclusion of the study, every patient entered into the study should be assured of access to the best proven prophylactic, diagnostic and therapeutic methods identified by the study. ${ }^{, 67}$

The paragraph was limited to patients and implied that clinical trial participants were the only ones who were entitled to benefit from post-trial access to the developed products.

In 2004 the following note of clarification was added to the Declaration:

'The WMA hereby reaffirms its position that it is necessary during the study planning process to identify post-trial access by study participants to prophylactic, diagnostic and therapeutic procedures identified as beneficial in the study or access to other appropriate care. ${ }^{68}$

This note of clarification added the phrase 'access to other appropriate care' and changed the term 'patients' to 'study participants', which means that the scope of benefits is extensive and healthy volunteers can also benefit from post-trial access.

The 2008 version of the Declaration changed the concept from 'post-trial obligation' to 'post-study obligation' and introduced two additional paragraphs; 14 and 33 which relate to benefit sharing and are relevant for the discussion in this paper. Paragraph 14 states that

'The protocol should describe arrangements for post-study access by study subjects to interventions identified as beneficial in the study or access to other appropriate care or benefits.'

\footnotetext{
${ }^{65}$ Hayden C, Taking as Giving: Bioscience, Exchange, and the Politics of Benefit-sharing. Social Studies of Science 2007 vol. 37 (5): 729-758, at p.730.

${ }^{66}$ Hayden (2007), p.731.

${ }^{67}$ World Medical Association, Declaration of Helsinki: ethical principles for medical research involving human subjects. World Medical Association, 2000.

${ }^{68}$ World Medical Association, Declaration of Helsinki: ethical principles for medical research involving human subjects. World Medical Association, (2004).
} 
This paragraph essentially expanded the scope of beneficiaries to other volunteers who may not directly be involved in the clinical trials, which can include pre-clinical or epidemiological research participants as well.

Paragraph 33 stipulates that

'At the conclusion of the study, patients entered into the study are entitled to be informed of the outcome of the study and to share any benefits that result from it, for example, access to interventions identified as beneficial in the study or to other appropriate care or benefits.'

The most interesting aspect of this paragraph, which is relevant for the discussion in this paper, is the requirement to inform the participants regarding the study outcome. Such information conventionally takes the form of either positive or negative outcome of the study. Paragraph 33 can be used to argue in favour of the 'public goods' nature of CT data in so far as the participants are entitled to be informed of some of the contents that might be undisclosed if data exclusivity is recognized by regulatory authorities. Such contents can for instance relate to safety, efficacy and approval status of the substance that is being tested.

The Declaration also recognizes the publication of research results as an ethical obligation. Paragraph 30 provides that

'Authors, editors and publishers all have ethical obligations with regard to the publication of the results of research. Authors have a duty to make publicly available the results of their research on human subjects and are accountable for the completeness and accuracy of their reports. They should adhere to accepted guidelines for ethical reporting. Negative and inconclusive as well as positive results should be published or otherwise made publicly available. Sources of funding, institutional affiliations and conflicts of interest should be declared in the publication...' Emphasis added.

Authors, in this context, include clinical researchers who are obliged to ensure the publication of the research results, which may be included in the protected CT data. In this regard, clinical researchers have a very important role in fostering ABS by making the results publicly available as required by paragraph 30 of the Declaration.

Part of managing IPRs over CT data would thus require such researchers to ensure that for the benefit of clinical research participants, they reserve the right to publish the findings from the research expeditiously and any pharmaceutical industry sponsor that may have IPR interests in the results can equally be granted the right review the proposed publication in order to ensure that prospects of obtaining IPRs are not prejudiced by the publication. This approach is bound to raise some tension when dealing with pharmaceutical 
companies in view of some authors' recommendation to these companies to 'refrain from undertaking any actions that could result in the disclosure of data, for example, through publication of the data in an academic journal. ${ }^{69}$ The emerging tensions may need to be managed by balancing ethical obligations to research participants and collaborating researchers who are entitled to access the information with the commercial interests of pharmaceutical companies. In this regard, ethical obligations ought to take first priority in the interest of public health. Article 39.3 of TRIPS in fact contains two exceptions that can be used in this balancing act. In terms of these exceptions, the information can be disclosed 'where necessary to protect the public', or [where] steps are taken to ensure that the data are protected against unfair commercial use.'

Admittedly, there is no agreement on what constitutes unfair commercial use of test data but Correa provides very useful examples that can be used in the above balancing act. He states that unfair commercial use 'may include competitor's misrepresentation, fraud threats, defamation, disparagement, enticement of employees, betrayal of confidential information commercial bribery... ${ }^{70}$ These examples can help authors in making decisions on the publication of clinical trial results and guide regulatory authorities on sharing information that may have public health relevance.

The two main parties whose interests are at stake in CT are the pharmaceutical companies that invest in CTs in order to deliver products to the end users and the communities that expect to benefit from the research. Both parties have their legitimate expectations. The pharmaceutical companies 'demand rules and enforcement that will protect their income streams, justifying a high return on the investment as necessary to drug development...[while the] community demands rules and measures to reduce the social cost of patents, to reduce expenses for governments, businesses and individual consumers, as well as to exercise greater control over the direction of research. ${ }^{, 71}$ 'Communities' in this context includes stakeholders such as researchers who expect to share information with their peers since 'scientific communities thrive on collaboration, which requires sharing information. ${ }^{, 72}$

\footnotetext{
${ }^{69}$ Lemmens T \& Telfer C, Access to information and the right to health: the human rights case for clinical trials transparency American Journal of Law and Medicine 2012, vol. 31(1), p.29 available at http://ssrn.com/abstract=1932436 the authors do however acknowledge the importance of a system of transparency of data 'for the promotion of evidence-informed medicine and the protection of public health.' See p.40.

${ }^{70}$ Correa CM, Protection of Data Submitted for the registration of pharmaceuticals: Implementing the Standards of the TRIPS Agreement, South Centre, Geneva, 2002, p.41.

${ }^{71}$ Abbott (2006), p.36.

${ }^{72}$ Lipkus BN, Mackie EJ and Singer AP, Guidance for reconciling patent rights and disclosure of findings at scientific meetings Health Research Policy and Systems 2010, vol. 8(15), available at http://www.health-policysystems.com/content/8/1/15
} 
As these expectations play out in the field of clinical research, they shift the spotlight to the need to manage IPRs over CT data with a view to meeting the parties' legitimate expectations. A starting point for discussing the management of IPRs would be to consider Gibson's argument that 'in order to deliver the right to health, not only must the possible limitations on access to products be addressed, but also the influences and factors relevant to the innovation process itself., 73

Notably, IPRs play an important role in the innovation process. For instance, Gibson argues that 'access is not necessarily restricted by the intellectual property framework itself... [since] arguably the patent system provides for access in industries where the same knowledge would otherwise be protected by trade secrets. ${ }^{74}$ This argument is reinforced by Taubman's observation that the 'IP system itself is intended to be one means of producing public goods. ${ }^{, 75}$ He defines a public good as 'a technical economic concept, referring to goods that are not used up when anyone benefits from them ('non-rivalrous') and that no-one can be prevented from enjoying ('non-excludable'). ${ }^{76}$

In view of this consideration, the move to collocate 'clinical test data within the provisions regulating unfair competition, ${ }^{77}$ under Article 39.3 of TRIPS may be questioned. The collocation essentially provides separate and additional protection to CT data, as undisclosed information, while there may be underlying patent protection already for the product, which is being tested. This position is confirmed in the prevalent practice, in some Free Trade Agreements (FTAs) in terms of which exclusive rights over test data 'operates, in some cases, like a substitute for the patent protection, thereby removing from public domain products that should be freely available., ${ }^{78}$

Reichman mentions a very valid concern regarding the above collocation in so far as it implies that 'the pharmaceutical industry has quietly but successfully pursued this alternative intellectual property right in the results of clinical trials, independent of and cumulative with the patent rights that everyone takes for granted. ${ }^{, 79}$

\footnotetext{
${ }^{73}$ Gibson J, Intellectual Property, Medicine and Health: current debates. Ashgate Publishing Company, Surrey, 2009, p.142.

${ }^{74}$ Gibson (2009), p. 142.

${ }^{75}$ Taubman (2011), p.165.

${ }^{76}$ Taubman (2011), p.165.

${ }^{77}$ Reichman (2009), p.19.

${ }^{78}$ Correa (2006), p.95.

${ }^{79}$ Reichman (2009), p.6.
} 


\section{Managing intellectual property rights over clinical research data}

The fact that TRIPS as an international standard setting instrument does not confer exclusive rights over CT data but leaves member states free to manage these issues essentially means that there is space for considering other management strategies for IPRs over such data. The second basis for making free decisions over the management of CT data should be Article 7 of TRIPS, which provides that

'the protection and enforcement of intellectual property rights should contribute to the promotion of technological innovation into the transfer and dissemination of technology, to the mutual advantage of producers and users of technological knowledge and in a manner conducive to social and economic welfare, and to a balance of rights and obligations'.

Brazil's Superior court of Justice's decision in the National Health Surveillance Agency (ANVISA) and Lundbeck, which has been discussed in this paper, illustrates how rights and obligations of parties ought to be balanced in practice.

The management of IPRs over clinical test data is viewed in this paper in a more practical manner by including the ethical principle of BS. This approach is in line with the nature of such data as 'public goods' and such public goods, as Taubman correctly argues, 'are not achieved through theoretical legal debate or even the formulation of binding international law. They are ultimately practical concerns, a consequence of the accumulated impact of numerous discrete choices and practical steps. ${ }^{80}$ Taubman further observes that 'much controversy and analysis of these issues and the formal legal options available to governments occur downstream and in international or bilateral contexts, often at a distant remove from the core context of the practice of regulation. ${ }^{81}$ A related and even more concise argument is advanced by Reichman who is of the view that in terms of Article 39.3 of TRIPS, 'WTO Members have no duty to "require...the submission of undisclosed test or other data." If a state foregoes such a requirement-for example, by relying upon the health and safety decisions of other jurisdictions or on the published medical literature, or a combination of both-it arguably incurs no liability whatsoever under Article 39.3. ${ }^{82}$

The above observations and arguments are helpful for locating the right level at which the management strategies that are proposed in this paper should be implemented. Taubman and Reichman in fact provide a solid basis on which it is argued in this paper that research consortia, regulatory authorities and technology transfer offices (TTOs) can adopt strategies

\footnotetext{
${ }^{80}$ Taubman (2011), p.169.

81 Taubman (2008), p.595.

${ }^{82}$ Reichman HJ, The International Legal Status of Undisclosed Clinical Trial Data: From Private to Public Goods? In Roffe P, Tansey G and Vivas- Eugui (eds) Negotiating Health: intellectual property and access to medicines. Earthscan Publications, London, 2006, p.141.
} 
that can foster the expeditious publication of results from clinical research thus sharing scientific information with peers and other stakeholders. Regulatory authorities can in turn rely on such scientific information for the approval of registration of products by competitors, based on the published information. This approach can also address safety and ABS concerns since the information would be available to other researchers who can replicate it and expedite the approval process for new products without having to contend with the intricate data exclusivity debates.

The concern, which has been raised by Lemmens and Telfer, that 'regulators of smaller countries with limited resources for drug approval may find it difficult to conduct a serious investigation in the source of the data when a generic drug company submits these to support an application ${ }^{, 83}$ can equally be addressed through this approach since the authorities would be relying on published scientific information as opposed to purely test data submitted by an originator whose authenticity may be difficult to verify.

Attempts to create clinical trial databases, which could deal with concerns relating to data exclusivity, are yet to yield tangible results as these attempts still face resistance on the basis that 'posting results on unapproved compounds or new applications of marketed products could erode intellectual property protections. ${ }^{, 84}$ This is the position notwithstanding the recognition of the fact that 'timely and transparent reporting of clinical trials results is essential to effective healthcare decision-making and public confidence. ${ }^{85}$

In situations where significant progress has been made towards disclosure of clinical trial information, some sectors of the pharmaceutical industry, particularly in Canada, have committed to disclosing 'results of exploratory trials where results are deemed to have significant medical importance or impact on labeling. ${ }^{86}$ Such limited disclosure is based on ' $[\mathrm{t}$ ]he argument...that if a product does not go to market, it does not affect health care decisions. ${ }^{, 87}$ The argument is not plausible because the disclosure of such information is not only required for health care decisions but influence the conducting of clinical trials such that non-disclosure leads to the duplication of clinical trials with a view to establishing anew the undisclosed information. As already pointed out, the duplication of clinical trials raises ethical concerns. The publication of such information is equally an ethical obligation under paragraph 30 of the Declaration of Helsinki.

\footnotetext{
${ }^{83}$ Lemmens \& Telfer (2012), p.35.

${ }^{84}$ Fisher BC, Clinical Trials Results Databases: Unanswered Questions. Science vol.311 (13 January) 2006: 180181 at p.181.

${ }^{85}$ Fisher (2006), p.181.

${ }^{86}$ Health Canada (2005), p.21.

${ }^{87}$ Health Canada (2005), p.21.
} 
A number of suggestions have been given in literature on how IPRs over CT data can be managed for public health benefits. These are explained below.

i. It is important to draw a distinction between the data itself and the 'health and safety outcome to which the data lead.

Reichman for instance argues that 'governments that merely cross-reference the conclusions reached on the basis of data submitted elsewhere, or that allow competitive production of bioequivalent products for local consumption once marketing approval has been granted, will arguably not have committed any actionable 'unfair commercial use' of regulatory data submitted by any firm, domestic or foreign within the purview of Article 39.3. In such cases, it is not the confidential data themselves that are being unfairly used, even if a first comer is compelled to submit them in order to meet health and safety requirements. It is the health and safety outcome to which the data lead that is being used (a matter of public record...)., ${ }^{88}$

\section{ii. Cost-sharing approach}

Reichman suggests that this should be 'built around the "take and pay" liability rules for value-adding uses of innovation... ${ }^{, 89}$ He argues that 'if this approach were applied to clinical trials, it would at the very least allow governments and third parties to rely upon both test data and positive regulatory outcomes for authorizing the marketing of equivalent or competing products otherwise permitted under international intellectual property law, provided that the second comers paid a reasonable royalty to the data originators to help defray their costs of $\mathrm{R}$ \& D. ${ }^{, 90}$ This approach is equally supported by Weissman who argues that the payable amount by the competitors 'is based on the actual cost of generating the data and the proportionate global market share obtained by the generic competitor. ${ }^{\text {91 }}$

Reichman and Weissman's suggestions essentially address concerns about free-riders, which were mentioned earlier. The suggestions can however be contested on the basis that clinical research data have a public good character, coupled with the fact that the exact costs of R\& D that are incurred in generating such data has not been established with precision. Pugatch has attempted to offer an explanation that could be used to counter these contentious arguments by observing that 'even if there is no academic consensus about the accurate costs

\footnotetext{
${ }^{88}$ Reichman (2006), p.142.

${ }^{89}$ Reichman (2006), p.145.

${ }^{90}$ Reichman (2006), p.145.

${ }^{91}$ Weissman (2006), p.155.
} 
of pharmaceutical R \& D, clearly the process of developing and testing a new pharmaceutical product, including clinical trials, requires major financial resources and time. ${ }^{92}$ The observation is however skewed towards favoring pharmaceutical industry's commercial interests without adequate public health considerations.

So far, the approach of cost-sharing has been tested in agricultural chemical registration (in the USA) ${ }^{93}$ but such chemicals differ significantly from the CT data context. The contribution of research participants to the generation of CT data cannot certainly be adequately factored into the actual costs that the approach relies on in advocating this TRIPSplus strategy.

A second, and rather revolutionary, suggestion by Reichman is to treat clinical trials as a public good. He argues that 'if clinical trials were properly viewed and treated as a global public good, it would still be necessary for governments around the world who participated in such a scheme to contribute a fair share to the aggregate costs of clinical trials, adjusted for the relative capacities to pay and to per capita gross domestic product (GDP). ${ }^{94}$

\section{iii. Public health variants of the data-exclusivity approach}

Broad consensus exists on the fact that test data, which includes CT data, are public goods. ${ }^{95}$ On the basis of such consensus and due to the fact that TRIPS is 'not a kind of model domestic law, ${ }^{96}$ there is space for countries to provide for public health variants to the dataexclusivity approach. The seven variants that have been proposed in literature are explained below.

a) Restricting data exclusivity to products consisting of new chemical entities (NCEs) and not to all new pharmaceutical products

The rationale for this approach is that '...the investment for reformulated products, products sold for new indications or derivative products will be less than for NCEs. ${ }^{97}$ The approach is in line with Article 39.3 of TRIPS to the extent that the Article only requires the protection of test data in relation to products that utilize NCEs. However, the idea of data exclusivity is a TRIPS-plus proposal with no adequate support since 'protection' is not equivalent to granting data exclusivity status.

\footnotetext{
92 Pugatch (2006), p.116.

${ }^{93}$ Weissman (2006), p.156.

${ }^{94}$ Reichman (2006), p.147.

${ }^{95}$ See Reichman (2009), Taubman (2008).

${ }^{96}$ Taubman (2008), p.601.

${ }^{97}$ Weissman (2006), p.163.
} 
b) Restricting data exclusivity to unpublished information

This approach would allow generic firms to gain market authorization 'if they are able to establish bioequivalence to products to which safety and efficacy has been shown in published literature. $^{, 98}$

The approach would require the contribution of researchers/collaborating consortia to facilitate the publication of information. Weissman argues that 'tying data exclusivity to lack of disclosure gives pharmaceutical companies an incentive not to publish their clinical testing data. ${ }^{99}$ In this case, researchers and TTOs need to be strategic in the licensing and clinical trial agreements by ensuring that terms that would facilitate data sharing with the scientific community are included. A good example of this approach can be learnt from Unitectra, a Swiss technology transfer organization, which supports scientists of the Universities of Basel, Bern and Zurich and of their associated university hospitals in their collaborations with industry and the commercialization of research results. ${ }^{100}$

Unitectra ensures that the researchers' right to publish research results is clearly provided for in the clinical trial and research agreements. In the case of sponsor/investigator initiated trials, the investigator's university reserves full publication rights. Publication may however be delayed for a period of three months to enable a collaborating party to apply for the patenting of any related invention. In cases where the trial is initiated by a commercial company, it reserves the right to review the data but if the company does not publish the data within a period of one year, then the collaborating university reserves the right to do so with a view to facilitating data sharing. ${ }^{101}$ Unitectra's role has been hailed in Europe ${ }^{102}$, which is a clear confirmation that researchers and TTOs can play an important role in the management of IPRs.

c) Waiving data-exclusivity protection in cases of compulsory licensing related to patents

Generic companies are usually required to obtain marketing approval even under compulsory licences. Data exclusivity would be an obstacle in such cases. ${ }^{103}$

\footnotetext{
${ }^{98}$ Weissman (2006), p.167. This is already practised in Chile, Colombia as well as a number of countries in Eastern Europe and Asia.

${ }^{99}$ Weissman (2006), p.168.

${ }^{100}$ Information about Unitectra is available at http://www.unitectra.ch/index.php?lang=en

${ }^{101}$ Personal discussion with Ms Aleksandra Goes and Dr Daniel Gisi; contract manager and technology transfer manager respectively at Unitectra's Bern office on $24^{\text {th }}$ November 2011.

${ }^{102}$ Swiss Technology Transfer Organisation Unitectra wins the 2011 European BIOTECHNICA Award, Biotechnica 2011 (11-13 October), pp.1-3. The BIOTECHNICA award recognized Unitectra's exceptional contribution to the initiation and promotion of cooperation between the publicly funded research community and business.

${ }^{103}$ Weissman (2006), p.169.
} 
d) Waiving data-exclusive protection for patented products

The basis of such waiver is that data originators already have patents to help them recoup their investment costs. ${ }^{104}$

e) Compulsory licensing system for registration data

The proposal in this case is that countries should be free to determine conditions under which compulsory licenses should be granted over registration data. ${ }^{105}$ Regulatory authorities can work together with TTOs, which ensure that terms that facilitate compulsory licensing are included in the licensing agreements.

\section{f) Shortening the term of data exclusivity}

This approach is already being used by Unitectra, which ensures that collaborating researchers at universities reserve the right to publish data if the commercialising company does not do so within a period of one year. Weissman also points out that a country can decide to shorten the term since the periods that are usually granted in practice are not based on any criteria. ${ }^{106}$

\section{g) Adjusting start date of data exclusivity}

Under this approach, the start date could be that of the first world-wide registration of the product in respect of which data exclusivity is granted.

The seven variants seem to promote equitable and fair access to data while respecting the underlying IPRs. However, given the public goods nature of CT data, might it not be more suitable to argue for the promotion of free access to such data? In posing this question, I am not oblivious to the current arguments in literature regarding the undesirable consequences of free-riding by competitors.

In view of the argument in this paper that clinical researchers can play an important role in data sharing in a manner that does not need to contend with data exclusivity complications, it is worth mentioning a practical suggestion that has been provided in literature, which can help researchers to share information from CT data freely. Lipkus and colleagues have suggested that early filing for patent rights can facilitate free sharing of information since subsequent disclosure does not compromise patentability. ${ }^{107}$ The difficulty with applying this suggestion to CT data sharing, particularly where the main reason for

\footnotetext{
${ }^{104}$ Weissman (2006), p.170.

${ }^{105}$ Weissman (2006), p.172.

${ }^{106}$ Weissman (2006), p.175.

${ }^{107}$ Lipkus et al., (2010).
} 
withholding data is the claim of exclusive rights over the data, is that the suggestion relates to patent rights while exclusive rights over data, as was pointed out earlier, are different the underlying patent rights.

iv. The misappropriation approach

This approach is intended to reflect TRIPS' flexibilities by providing for the non-disclosure of registration data while at the same time enabling generic companies to rely upon approval by regulatory agencies of originator products. ${ }^{108}$

In countries where this approach has been implemented, it prohibits disclosure of the data by government officials to third parties but 'they empower government agencies to grant marketing authorization by relying upon the fact of prior approval of essentially similar products for which registration data was submitted. ${ }^{109}$

The approach is advantageous for two main reasons; it 'enables generics to reach the market as fast as possible, and with no extra registration data-related costs [and it] is simple to administer as it imposes no regulatory burdens on governments. ${ }^{, 110}$

The approach however has its disadvantages too. For instance, Weissman argues that 'it will undermine brand name company investment in research and development... and...it denies fair return to brand name companies. ${ }^{, 11}$ This takes us back to the issues that were earlier noted in this paper regarding the contested R \& D costs in clinical trials and the 'public good' nature of CT data, particularly given that human participants equally contribute to the generation of the data.

At a practical level, experience shows that 'in bilateral and regional free trade agreement negotiations with industrialized countries, developing countries that have suggested little more than the misappropriation approach have found their positions unsustainable. 112

\section{Conclusions}

The two fundamental principles, which are the basis of data sharing that were mentioned earlier, namely; minimizing impediments to research processes and making the products of scientific research widely available to the people who need them should be used in assessing the suitability or otherwise of the management options that are discussed in the preceding part

\footnotetext{
${ }^{108}$ Weissman (2006), p.153.

${ }^{109}$ Weissman (2006), p.153.

${ }^{110}$ Weissman (2006), p.153.

${ }^{111}$ Weissman (2006), p.153.

${ }^{112}$ Weissman (2006), p.155.
} 
of this paper. The other factor to bear in mind is the fact that the strategies cannot work in practice if, as Lemmens and Telfer have correctly suggested, changes do not target international trade regimes as well in view of the fact that 'existing international trade agreements oblige countries to respect the secrecy of clinical trials data and are invoked to resist trial registration and results reporting obligations. ${ }^{113}$ This definitely calls for the correct understanding and interpretation of Article 39.3 of TRIPS, which would enable countries to exercise more freedom in negotiating FTAs and in enforcing data exclusivity related claims at the domestic level. The Brazilian approach in the case of the National Health Surveillance Agency (ANVISA) and Lundbeck provides a good example in this regard.

Apart from changes that are aimed at the international trade regimes, strategic approaches can be used by researchers, TTOs and regulatory authorities since they are better placed to apply the paramount ethical principle of BS in their daily operations and would also appreciate the fact that research participants' and public health interests should be considered in decision making.

The main strategic approaches that have been identified in this paper are summarized below.

i. Researchers should ensure that they reserve the right to publish clinical research findings expeditiously when they sign clinical trial agreements and TTOs that negotiate licensing agreements with the pharmaceutical industry, on behalf of researchers, should equally be sensitized on the need to protect this right since it is an ethical obligation under paragraph 30 of the Declaration of Helsinki.

ii. Regulatory authorities should exercise discretion by drawing a clear distinction between the data itself and the 'health and safety outcome to which the data lead. This approach should enable the regulatory authorities to exercise the freedom to register competing products based on proven health and safety outcomes if bioequivalence can be established by the applicant. This is acceptable under Article 39.3 of TRIPS.

iii. Regulatory authorities should be allowed through domestic legislation to rely on published scientific information to approve competitors' products. As was noted earlier, TRIPS is not a model law to be copied at the domestic level and due to the contested interpretations of Article 39.3, it would be useful for countries to provide clarity in their legislations, which would enable regulatory authorities more freedom in decision making.

\footnotetext{
${ }^{113}$ Lemmens \& Telfer (2012), p. 43.
} 